\title{
Experimental Study of Centrifugal Compressor Tip Clearance and Vaneless
}

\section{Diffuser Flow Fields}

\author{
Ahti Jaatinen-Värri, Teemu Turunen-Saaresti, Pekka Röyttä, Aki Grönman, and Jari Backman \\ Institute of Energy, Lappeenranta University of Technology, P.O. Box 20, FI-53851 Lappeenranta, \\ Finland
}

\begin{abstract}
Three vaneless diffuser designs, varying in diffuser width, for centrifugal compressor were studied experimentally. Along with the diffuser width, the tip clearance was altered. The compressor overall performance and diffuser flow fields were studied for each of the three diffusers at four different tip clearances. For the diffuser flow fields, the total pressures were measured with probes traversed over the diffuser width both at the diffuser inlet and outlet. Along with the total pressures, the static pressures were measured adjacent to the probes. This enabled the axial flow angle and velocity distributions to be studied. The pinches tested improved the stage efficiency mainly by suppressing the secondary flow region present near the shroud at the impeller outlet. This leads to a lower strain rate, resulting in lower losses. The efficiency decrease due to the increased tip clearance was similar with and without pinch present. This indicates that in the diffuser, the main source of the tip clearance associated losses is the tip jet, and the tip clearance vortices mix out already in the impeller.
\end{abstract}

Keywords: centrifugal compressor, tip clearance, vaneless diffuser, flow field 


\section{INTRODUCTION}

The ever increasing demand for more energy efficient systems and components sets new prerequisites for designers to meet the needs without reducing the capacity of machines or excessively increasing the manufacturing costs. Centrifugal compressors are widely used for example in the process industry, refrigeration processes, waste water aeration, and internal combustion engine turbo chargers. Finding ways to improve centrifugal compressor efficiencies can offer a substantial potential to save energy.

The performance of the impeller is already relatively high, and the prospects for improving the compressor stage overall performance lie mainly in the improving of the diffuser performance [1, 2].

Centrifugal compressors are commonly equipped with vaneless diffusers when a wider operating range and lower manufacturing costs are desirable. It is a rather common design practise to include a pinch, i.e. to reduce the diffuser width after the impeller exit. It is well established that the diffuser width has a crucial effect on the critical flow angle entering the diffuser, and that reducing the diffuser width allows a more tangential impeller outflow [3, 4]. The critical flow angle means the maximum deviation of flow from the radial direction at the impeller outlet with which the diffuser operates under stable conditions.

The effect of the diffuser width on the stage performance is not completely understood. Experiments with excessive width reductions have shown that the stage efficiency deteriorates as the diffuser width is reduced [5-8]. On the other hand, two parallel wall diffusers were studied experimentally by Di Liberti et al. [9]. The diffusers had widths of 9.40 and $11.18 \mathrm{~mm}$, the narrower having somewhat better efficiency. A $15 \%$ width reduction had no effect on the impeller performance. The impeller exit width was not disclosed in the article. 
A recent, more extensive study by the authors [10] showed that implementing the pinch (reducing the diffuser width) clearly improved the stage efficiency and pressure ratio, and that the pinch implemented in the shroud is more beneficial to the stage performance than the width reduction divided between the hub and shroud would be. Also, if the shroud pinches of two cases were the same, an additional hub pinch present in the other case would have only a minor effect. In another study by the authors it was concluded that the pinch increases the impeller efficiency, but decreases the diffuser performance [11]. All in all, with moderate pinches it is possible to increase the stage efficiency.

As the effect of the diffuser width on the compressor performance is not straightforward, the highly complex flow at the impeller outlet must be taken into account in considerations. The flow in the centrifugal compressor vaneless diffuser has been studied experimentally by Pinarbasi and Johnson [12-14]. The results show that the blade wakes mix rapidly with high momentum jet flow in the diffuser whilst the passage wakes mix out slowly. The circumferential variations also mixed out rapidly whilst the axial variations tended to persist. Similar conclusions were drawn also at offdesign conditions, except above the design mass flow rate where stronger secondary flows prevented the rapid mixing of the circumferential variations. Stress tensor measurements showed that although the turbulent kinetic energy levels in the passage wake are as high as those in the blade wake, the off-diagonal elements of the Reynolds stresses were weaker, i.e. the turbulence had a weaker anisotropy, and hence, the passage wake mixed out slowly. In a more recent study [15], four regions in the impeller outlet flow were identified as potential sources of loss. The regions were the blade wake, the shear layers between the passage wake and jet, the thickened hub boundary layer, and the interaction region between the secondary flow within the blade wake with the passage vortex. 
The passage wake or secondary flow region is highly affected by the tip clearance flow. It has been universally long known that increasing the tip clearance decreases the compressor efficiency and pressure ratio [16-18]. For example in a recent study, Hong and Abhari [19] got a slope of 0.37 for the efficiency drop due to the increasing tip clearance, meaning approximately one percentage point drop in efficiency for every three percentage point increase in the relative tip clearance. In a study of Turunen-Saaresti and Jaatinen [20] in which an array of studies was looked through, it was noted that the slope for the efficiency drop varied between 0.2 and 1.05 for different compressors. The efficiency drop depends on the compressor operating point. At higher mass flows, the efficiency drop is higher due to the increased tip clearance [21, 22].

Flow field measurements with LDA in the vaneless diffuser of a centrifugal compressor showed that the tip clearance affects the diffuser flow field [23]. With a reduced clearance, there was no flow reversal at the shroud, and the tangential velocity in the wake was lower. With larger clearances the wake was larger and located closer to the hub.

Three different tip clearance ratios for a high-speed and high pressure ratio centrifugal compressor were studied by Wang et al. both numerically and experimentally [24]. The clearance ratio was varied from 0.073 to 0.116 . The increased tip clearance led to a growing secondary flow region. This secondary flow region moved towards the central of the flow channel leading to a negative impact on the mainstream flow. Also, the higher entropy increase was observed in the secondary flow region with the larger tip clearances. The effect of the tip clearance was found to be small at partial speeds. The impeller deformation due to thermal and mechanical loads was also studied, and it was found to decrease the tip clearance, hence improving the compressor aerodynamic performance. However, neither the used solver nor the turbulence model was reported in the article, and the experimental uncertainties reported were relatively high. 
Fundamental aspects of the tip clearance flows in turbomachines have been discussed by You et al. [25]. The study included large eddy simulations of a linear cascade with a moving endwall. It was concluded that both the tip leakage jet and tip leakage vortex produce significant mean velocity gradients that contribute to the production of vorticity and turbulence kinetic energy, thus producing viscous losses. These velocity gradients were the main loss source. In our study, the pinch is assumed to suppress the tip leakage vortex in the diffuser and thus reduce viscous losses. Even though the study considered axial flow machines, the root causes for losses caused by the tip clearance flow are similar for both the radial and axial machines.

To study the possible effects the pinch has on the diffuser flow field, on the secondary flow, and therefore on the compressor performance, the loss mechanisms in the centrifugal compressors must be considered. Denton describes various losses in different types of turbomachines [26]. Centrifugal compressors are closely adiabatic, thus only the entropy creation by irreversibilities has a major contribution to the loss of efficiency. In turbulent boundary layers, most of the entropy generation occurs within the laminar sublayer and the logarithmic region. Other sources of losses in the diffuser are the mixing of blade and passage wakes, and the losses increase with the swirl angle at the impeller outlet.

In this paper, the effect of the diffuser width reduction after the impeller exit is studied experimentally together with varying tip clearances. This offers new insights about the centrifugal compressor tip clearance flow, and whether it is dominated by the tip clearance vortex or jet. In addition, the reasons why moderate pinches improve the centrifugal compressor stage efficiency are studied. The combined effects of the pinch and tip clearance on the diffuser flow fields are studied for the first time. The aim of the work is discussed in more detail in the following chapter. 


\section{HYPOTHESIS}

From the above-mentioned it can be deduced that a moderate shroud pinch after the impeller outlet improves the centrifugal compressor stage performance. The pinch improves the performance 1) by decreasing the secondary flow region, especially the tip-clearance vortex, present at the shroud reducing the viscous losses and turbulence kinetic energy production; and 2) by turning the flow more radial at the diffuser inlet reducing the swirl angle.

The implications of the first assumption of the hypothesis is that less kinetic energy of the flow is drained to turbulence and dissipated to heat after the pinch. This indicates higher total-to-total efficiency. Current knowledge of whether the increasing tip clearance increases the tip jet flow or tip vortex flow is insufficient. We seek to shed light on this matter. If the loss is mainly due to the tip jet, the pinch should have little effect on the efficiency decrease due to the increasing clearance, and if it is mainly due to the vortex, the effect should be well pronounced, given that the assumption is correct.

The implications of the second assumption are that the flow travels a shorter distance in the diffuser, and this should reduce viscous losses in boundary layers. On the other hand, as the area ratio of the diffuser inlet and outlet is irrespective of the diffuser width, the shorter flow path with the narrower diffuser leads to a higher $d A / l$ ratio. If the $d A / l$ ratio is too high, the flow separates in the diffuser, leading to a lower total-to-total efficiency in the diffuser, and negating the effect of the first assumption. The flow fields should be different between the two cases. If the flow separates due to a too large opening angle, the velocity deficit should be present near both walls. If the losses are due to the tip-clearance vortex, the deficit is at the shroud wall. 
To test the hypothesis, three different vaneless diffusers varying in diffuser width are studied experimentally. In addition, to study the effects the width reduction has on the secondary flow, each diffuser is tested with four different tip clearances. It is believed that the positive effect of the pinch to the secondary flows can be seen more clearly at the increased tip clearance. Preliminary results for one of the diffusers have been presented in 2012 [27].

The overall stage performance and detailed flow fields are studied. A detailed description of the studied designs and the measurement setup is given later.

\section{STUDIED DESIGNS AND EXPERIMENTAL SETUP}

\subsection{Studied Designs}

The original design had an unpinched diffuser $b /\left(b_{2}+t_{2}\right)=1.00$ and a relative tip clearance $t_{2} / b_{2}$ of 0.027. The tip clearance was increased by shimming the shroud side casing. This leads to somewhat increased diffuser width. However, in a previous study [10] it was concluded that small changes in the diffuser width do not significantly affect the compressor performance or diffuser flow fields. After the measurements with the original unpinched diffuser, the pinch was implemented by changing the shroud side diffuser plate, and four different tip clearances were tested again. The procedure was then repeated for the third diffuser.

The pinch began at the radius ratio $r_{2} / r_{2}$ of 1.01 . The studied designs and tip clearances are summarised in Table 1, and a schematic view of the diffuser is presented in Figure 2. 
Table 1 Studied designs

\begin{tabular}{lccc}
\hline Case & $t_{2} / b_{2}$ & $b /\left(b_{2}+t_{2}\right)$ & $r_{3} / r_{2}$ \\
\hline Case 1 & 0.027 & 1.00 & 1.68 \\
Unpinched & 0.053 & 1.00 & 1.68 \\
& 0.082 & 1.00 & 1.68 \\
& 0.106 & 1.00 & 1.68 \\
\hline Case 2 & 0.027 & 0.91 & 1.68 \\
$10 \%$ pinch at & 0.053 & 0.91 & 1.68 \\
the shroud & 0.082 & 0.91 & 1.68 \\
& 0.106 & 0.91 & 1.68 \\
\hline Case 3 & 0.027 & 0.85 & 1.68 \\
$15 \%$ pinch at & 0.053 & 0.86 & 1.68 \\
the shroud & 0.082 & 0.86 & 1.68 \\
& 0.106 & 0.86 & 1.68 \\
\hline
\end{tabular}

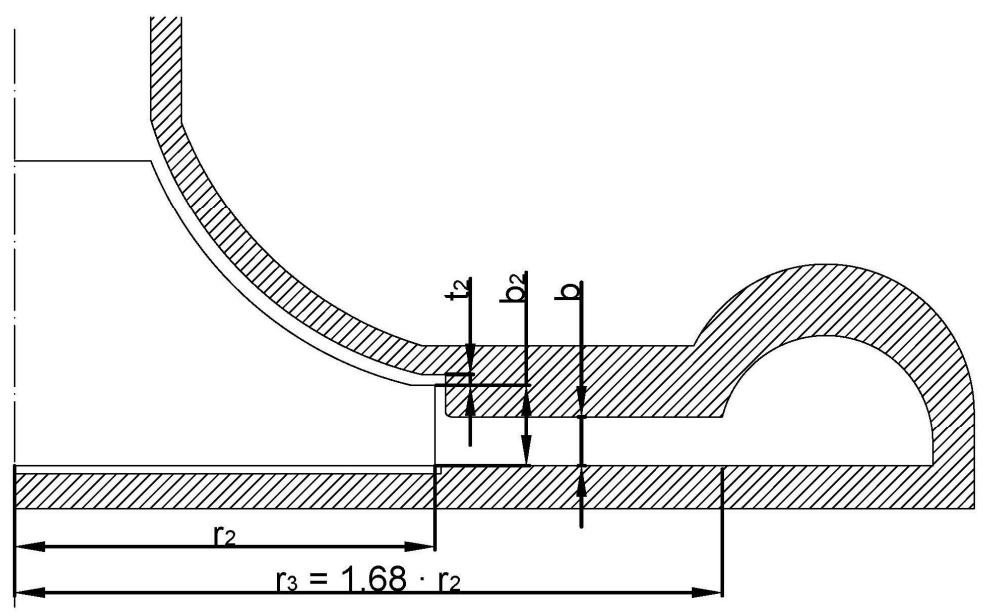

Fig. 1 Schematic view of the pinch and tip clearance

\subsection{Test Compressor and Measurement Setup}

The test compressor is a high-speed, variable speed driven compressor. The compressor is equipped with active magnetic bearings, and it has a design pressure ratio $\pi$ of 1.78 . The specific rotational speed is 0.8 , and it is defined as

$$
N_{\mathrm{s}}=\frac{\omega \sqrt{q_{\mathrm{v} 1}}}{\Delta h_{\mathrm{s}}^{0.75}}
$$


The impeller is unshrouded, and it has a $40^{\circ}$ back sweep at the impeller exit (from the radial direction) and seven full and seven splitter blades. The ratio of the impeller outlet height to the outlet radius $b_{2} / r_{2}$ is 0.1214 , and the diffuser outlet radius ratio $r_{3} / r_{2}$ is 1.68 . The diffuser height is constant over the diffuser length. The compressor is equipped with a volute, designed to provide a constant circumferential pressure distribution at the design operating point. The compressor intakes from and discharges into the atmosphere.

The mass flow was measured with an ISA 1932 nozzle made according to the DIN 1952 standard [28]. The instrumentation and performance calculations were carried out according to relevant standards [29-32]. The same compressor and test stand was used in the above-mentioned studies $[10,11]$

The test stand layout is shown in Figure 2. In the overall performance measurements, the temperatures and pressures before and after the compressor were measured with the temperature and pressure measurements of the test stand. The overall performance measurements were performed at three rotational speeds $N_{\text {ref }} / N_{\text {des }}$ of $0.95,1.00$, and 1.05 , from choke to near stall mass flows. The measurement uncertainties are summarised in Table 2.

The flow fields were measured at the design operating point. The flow field measurements were performed with a three-hole cobra probe and three Kiel probes. The total pressure and flow angles were measure with the cobra probe at one circumferential location opposite the volute tongue $\left(194^{\circ}\right)$, and the total pressures and temperatures with the Kiel probes at three other circumferential locations. The probe measurements were performed at the radius ratios $r / r_{2}$ of 1.054 and 1.67 at the diffuser inlet and outlet, respectively. The probes were traversed over the diffuser width. Static pressures were measured at the same radius ratios adjacent to the probe measurements. The position 
of the probe and static pressure measurements are shown in Figure 3, and the measurement uncertainties are listed in Table 2.

Table 2 Maximum instrument measurement uncertainty with $94.5 \%$ confidence interval

\begin{tabular}{lcl}
\hline quantity & error & \\
\hline mass flow & $\pm 0.17 \%$ & relative error \\
efficiency & $\pm 0.47 \%$ & relative error \\
pressure ratio & $\pm 0.33 \%$ & relative error \\
\hline flow angle & $\pm 1^{\circ}$ & absolute error \\
flow velocity & $\pm 3.8 \%$ & relative error \\
\hline
\end{tabular}

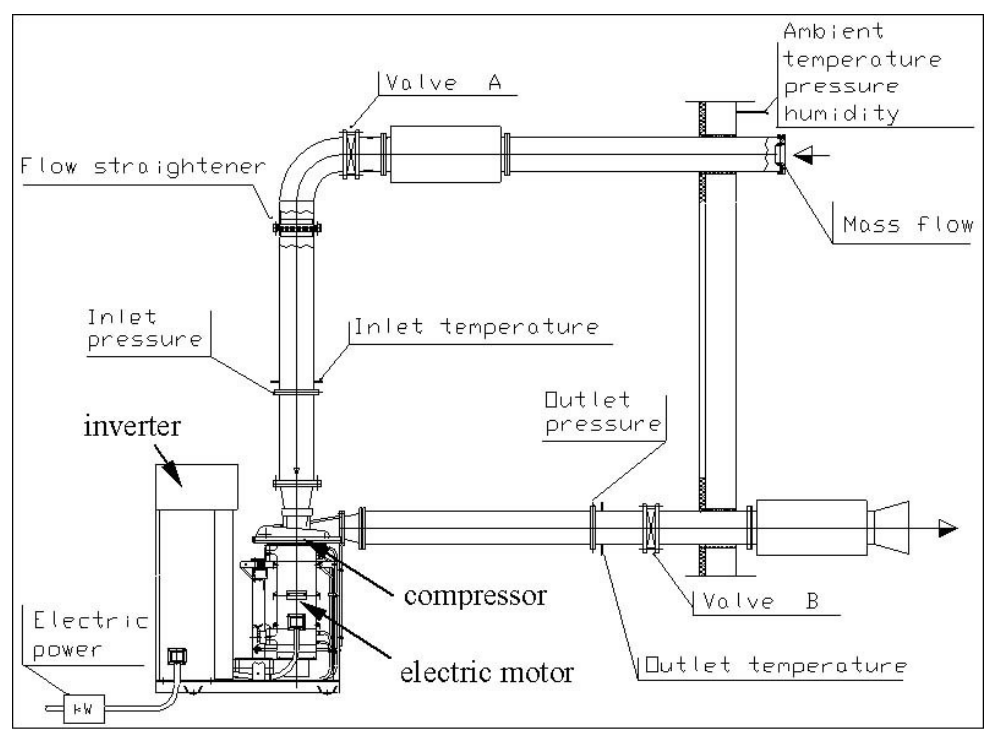

Fig. 2 The test stand layout 


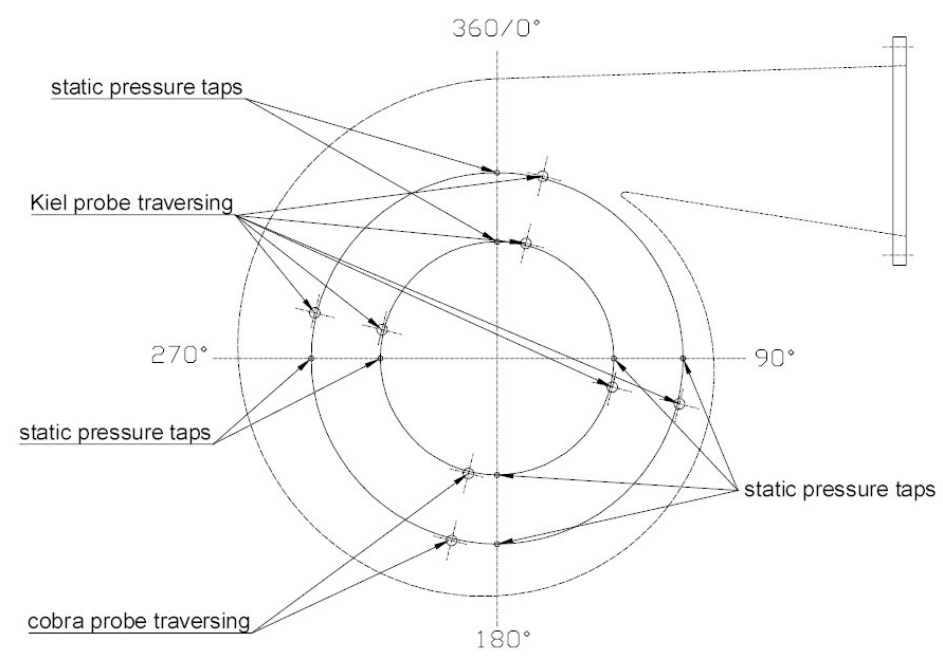

Fig. 3 Static pressure tap and probe traverse locations

\section{MEASUREMENT RESULTS}

\subsection{Overall Stage Performance}

The total-to-total stage efficiency is defined as

$$
\eta_{\mathrm{tt}}=\frac{T_{\mathrm{t} 1}\left(\pi_{\mathrm{tt}}^{R / c_{\mathrm{p}}}-1\right)}{T_{\mathrm{t} 5}-T_{\mathrm{t} 1}}
$$

The stage efficiency of Case 3 is presented as a function of the mass flow at the design rotational speed in Figure 4. The efficiencies are non-dimensionalised with the design efficiency of the original setup. As expected, the efficiency decreases as the tip clearance increases. The effect is highest at higher mass flows, and at lower mass flows, the changes in the efficiency are smaller. At the low flow, the changes in the efficiency between two successive clearances are in the magnitude of the measurement error. However, the trend is clear between the largest and the smallest clearances. The efficiency curves of two other cases are similar and hence not presented here. 


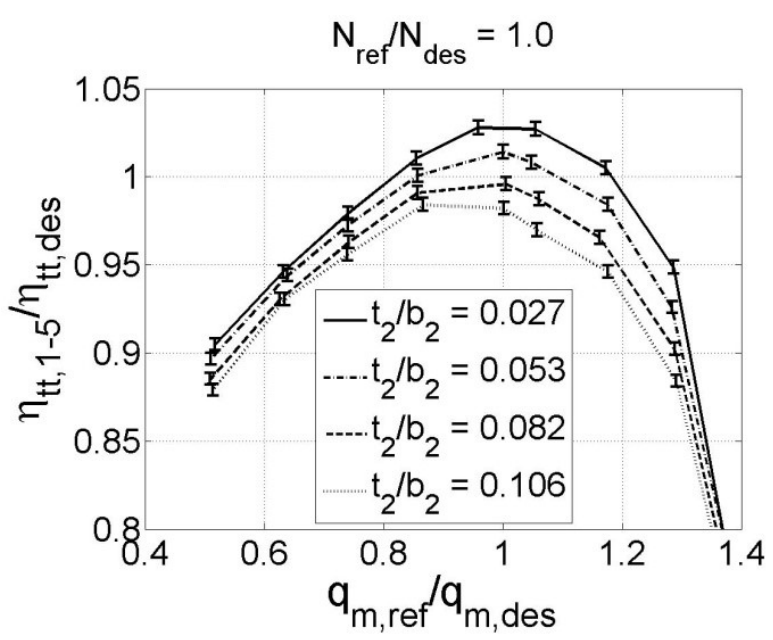

Fig. 4 Stage efficiency of Case 3 at the design rotational speed

The stage efficiency drop due to the increasing tip clearance at the design rotational speed at the design mass flow, 0.8 times the design flow, and 1.2 times the design flow is presented in Figure 5 . The base-line efficiency to which the other efficiencies are compared is always the efficiency of the unpinched design at the lowest tested tip clearance.

The efficiency drop due to the increasing tip clearance is lowest at the lower mass flow where the slopes of the efficiency curves are between 0.21 and 0.26 , and the differences between the different cases are the smallest, and changes in the efficiency between Case 1 and 2 and Case 2 and 3 are smaller or in the order of the magnitude of the experimental uncertainty. At the high flow, the efficiency drop is the largest; the slopes are between 0.69 for Case 3 and 0.85 for Case 1 . The differences in the efficiency for the cases 2 and 3 are again smaller or in the order of the magnitude of the experimental uncertainty, and the efficiency drop is similar for both cases. At the design flow, the efficiency drops are between that of the low and high flows (the slopes between 0.51 and 0.57). In general, the efficiency drop is the highest with the unpinched diffuser and lower with the pinched diffuser. The two pinched cases cannot be separated, as the differences in the efficiency are smaller or in the order of magnitude of the experimental uncertainty. 


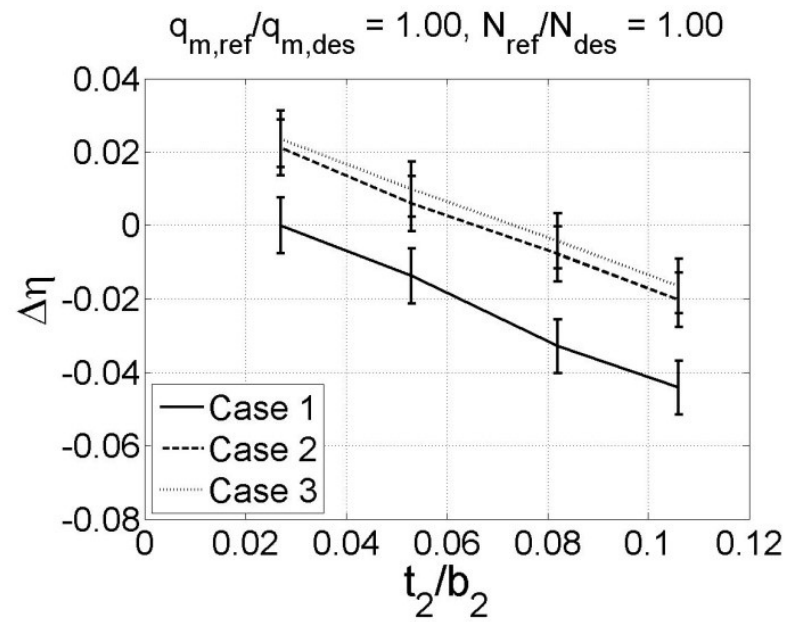

(a)

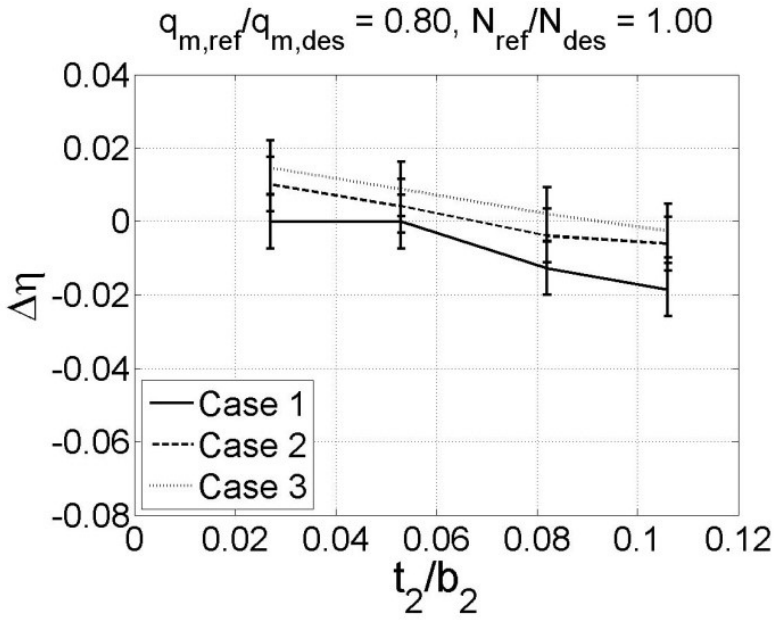

(b)

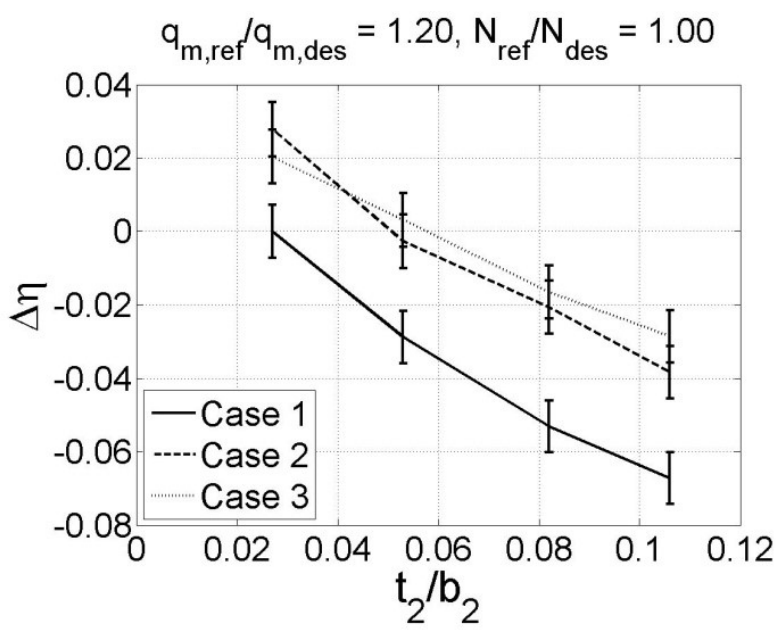

(c)

Fig. 5 The stage efficiency drop due to the increasing tip clearance at the design rotational speed (a) $q_{\mathrm{m}, \mathrm{ref}} / q_{\mathrm{m}, \mathrm{des}}=1.0,(\mathrm{~b}) q_{\mathrm{m}, \mathrm{ref}} / q_{\mathrm{m}, \mathrm{des}}=0.8$, and (c) $q_{\mathrm{m}, \mathrm{ref}} / q_{\mathrm{m}, \mathrm{des}}=1.2$

To study the effect of rotational speed, the efficiency drop at the design mass flow with two different rotational speeds is presented in Figure 6. The efficiency drop due to the increased tip clearance at the lower rotational speed is slightly higher than at the design or higher rotational speed. At the lower rotational speed, the slopes are between 0.61 for Case 1 and 0.57 for Case 3, and at the higher rotational speed, the slopes are between 0.5 for Case 1 and 0.37 for Case 3 . These 
differences in the slope are smaller than the experimental uncertainty. Assuming the maximum variation of the slopes due to the experimental uncertainty, it is possible that the differences between the slopes at the higher and lower rotational speeds are in the range of experimental uncertainty. However, this is highly unlikely. In the study of Wang et al. [24], it was concluded that at the lower rotational speeds the effects of the tip clearance were smaller, and here it seems to be the opposite. Wang et al. [24] also concluded that the deformation of the impeller reduces the tip clearance, improving thus the performance. The impeller deformation is larger with the higher rotational speed. This might explain why the efficiency drop seems to be larger with the lower rotational speed.

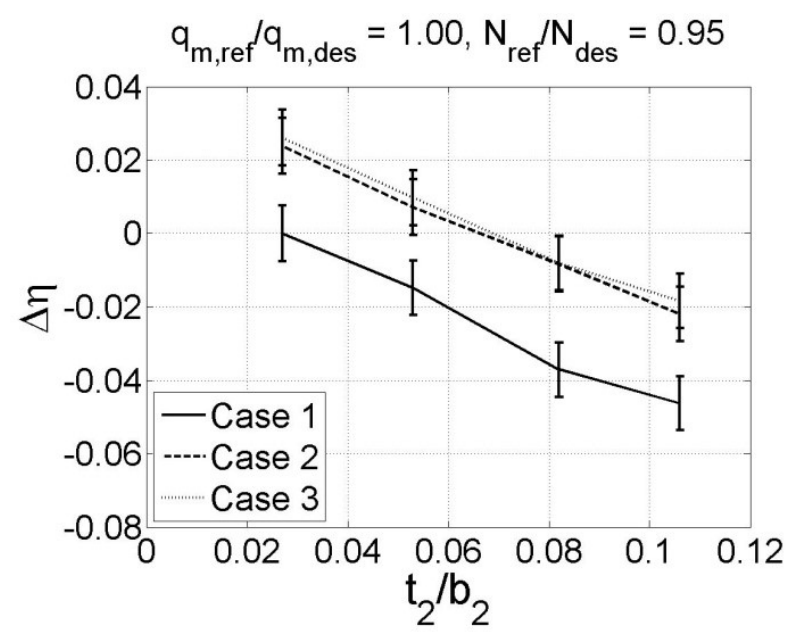

(a)

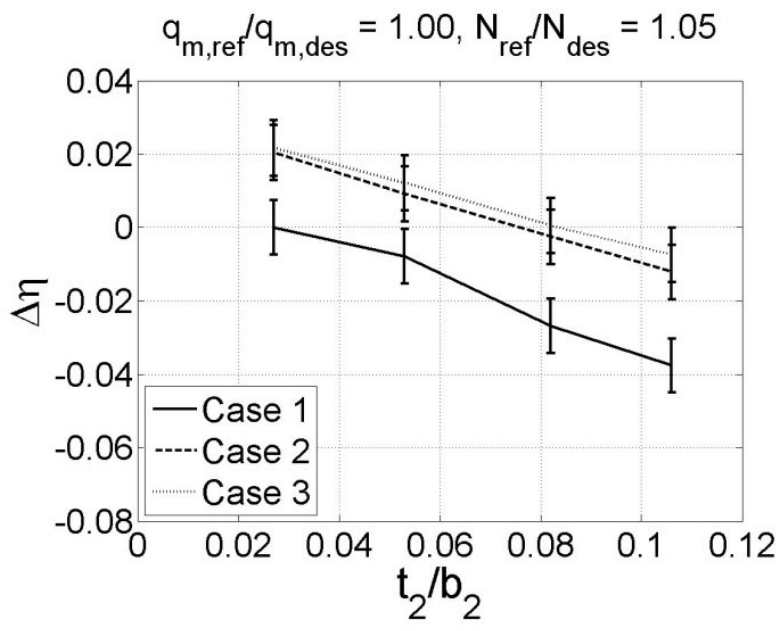

(b)

Fig. 6 The stage efficiency drop due to the increasing tip clearance at the design mass flow (a) $N_{\text {ref }} / N_{\text {des }}=0.95$ and (b) $N_{\text {ref }} / N_{\text {des }}=1.05$

Considering the role of the tip jet and the tip vortex in the efficiency decrease, only the high mass flow case shows a qualitative difference in the efficiency drop (Figure 5). In the other cases, the efficiency drops similarly with the increasing tip clearance. It is reasonable to speculate that at the high mass flows, the mechanisms which originate from the tip clearance are suppressed with the large pinch. Thus, the indications are that there is a constantly growing velocity deficit at the shroud 
that the pinch helps to eliminate, but it most likely is not due to the tip vortex, except maybe at the higher mass flows. Likely explanations are that either most of the efficiency decrease is due to the tip jet flow, or that the tip vortex flow is already mixed to the main flow in the impeller, in other cases than at the high mass flow. Unlike in the study of You et al. [25], the impeller shroud has a curvature which could intensify the mixing.

\subsection{Diffuser Flow Fields}

The absolute flow angles (defined from the radial direction) were measured with the cobra probe at the circumferential location of $194^{\circ}$. To investigate the differences between the cases and the effect the tip clearance has, the flow angles are presented at the diffuser inlet and outlet with the smallest and the largest tip clearances in Figure 7. At the diffuser inlet, Case 1 has a large backflow region near the shroud. With Cases 2 and 3, there is no such backflow region, and the flow turns less tangential due to the increasing tip clearance than with Case 1. Near the hub, the differences between the cases are small. With all cases, the flow angle near the hub is smaller when the tip clearance increases. As the tip clearance increases, the secondary flow area near the shroud increases. This forces the core flow towards the hub, causing more radial flow there. At the diffuser outlet, the differences between the three cases are smaller at the hub. The effect of the increased tip clearance is smallest with Case 3 and largest with Case 1 near the hub, and vice versa near the shroud. Near the shroud the differences in the flow angle due to the increased tip clearance are evidently higher with Case 3 . With the smallest clearance, Case 3 has the most radial flow, and with the largest clearance, it has the most tangential flow. 

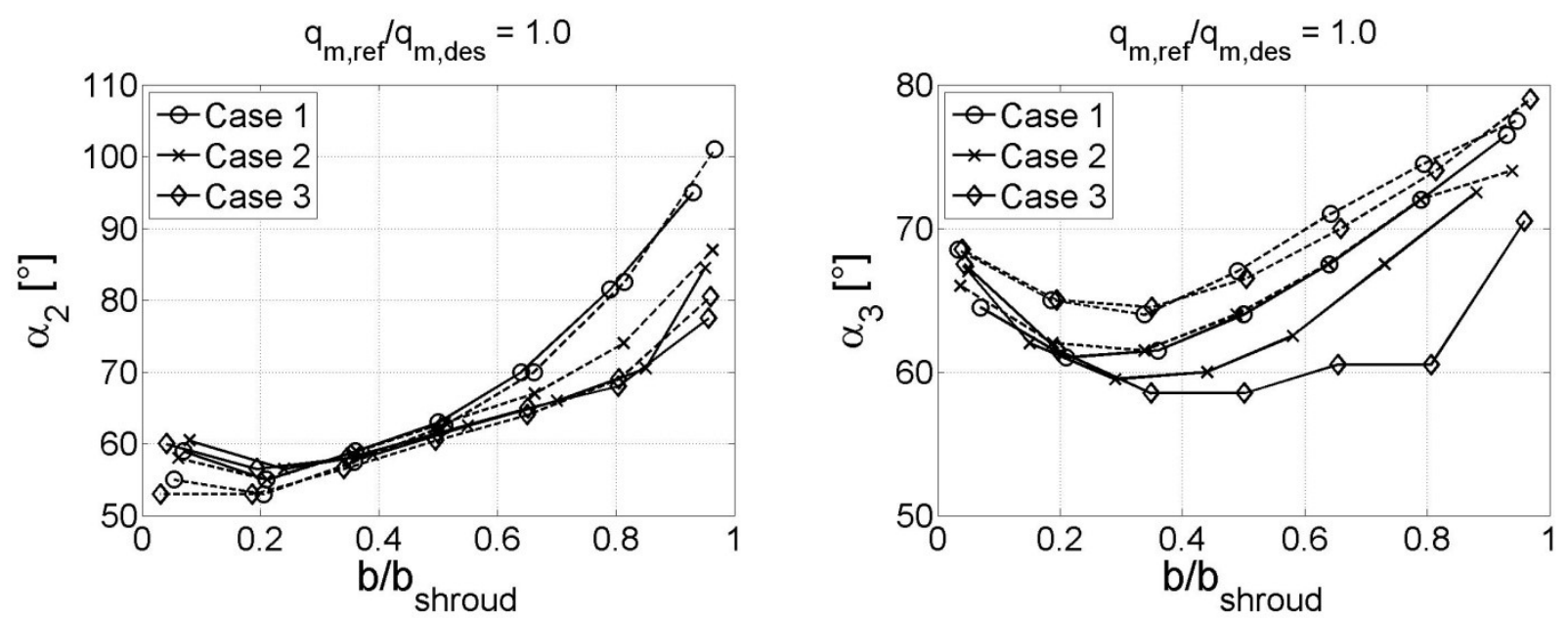

Fig. 7 Absolute flow angles at the lowest (solid line) and highest (dashed line) tip clearances, (a) diffuser inlet and (b) diffuser outlet

The absolute flow angles at the diffuser outlet at all tested clearances for all three cases are presented in Figure 8. As expected, the flow at the diffuser outlet is more tangential when the clearance is increased. The differences between the different clearances are minor for Cases 1 and 2 , the changes in the flow angle being approximately within $5^{\circ}$. The effect of the tip clearance on the flow angles at the diffuser outlet is most clearly seen for Case 3 . The changes in the flow angle due to the tip clearance near the hub are similar for Case 3 as they were for Cases 1 and 2 . However, near the shroud the flow is clearly more radial with the smaller clearances. It is speculated that this is due to a non-linear suppression of the separation at the shroud, i.e. at some point we get increasing benefits from the pinch, if the pinch is large enough and the separation small enough.

At the diffuser outlet, the tip clearance seemed to have a significant effect on the flow direction with the largest pinch. The effect was positive, as the flow was more radial and uniform. It can be speculated that in this case, the pinch suppressed some mechanism, namely the tip clearance vortex from mixing with the main flow and draining kinetic energy. This would be seen as an efficiency 
increase. Furthermore, the flow at the hub side was not separated; thus the increased $d A / l$ ratio did not cause separation with the pinches tested here.

The absolute flow velocity is calculated with the total pressures measured with the cobra probe, the static pressure measured with the closest static pressure tap, and the total temperatures measured with the two adjacent Kiel probes. The static pressure is assumed to be constant over the diffuser width.
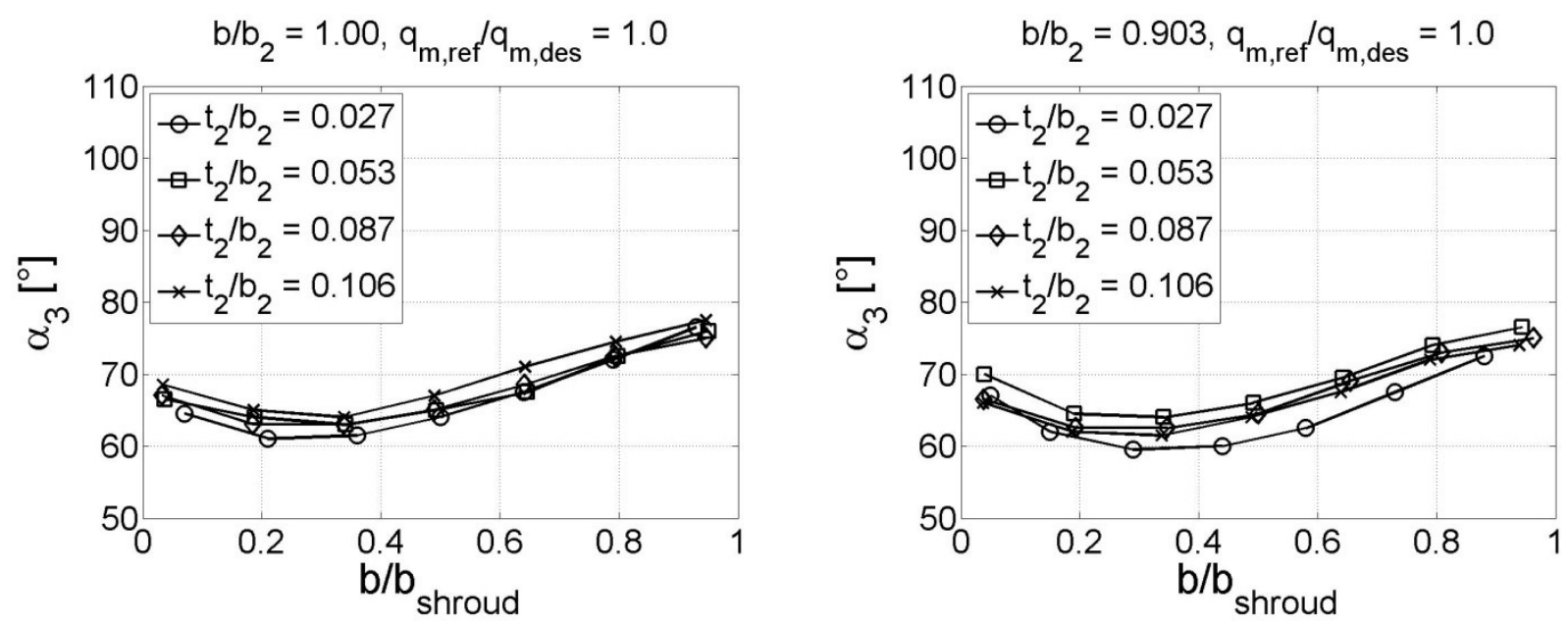

(a)

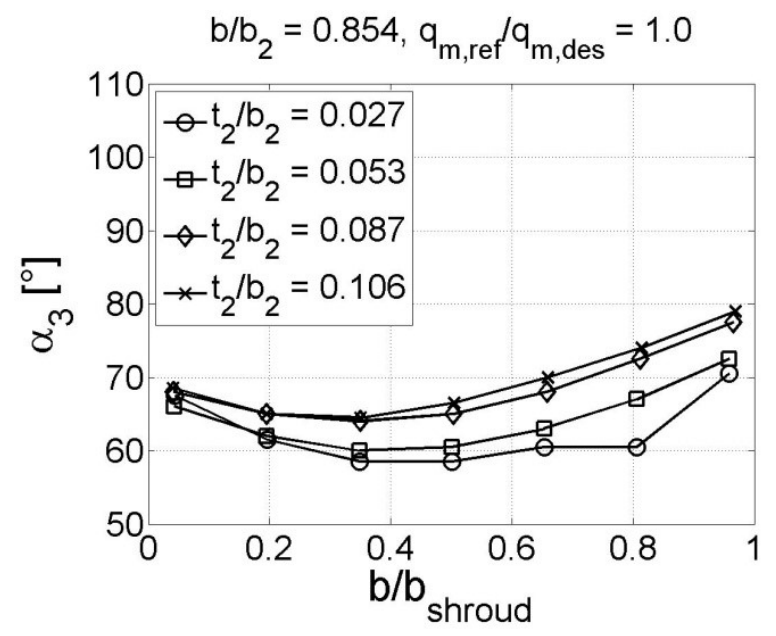

(c)

Fig. 8 Absolute flow angles at the diffuser outlet (a) Case 1, (b) Case 2, and (c) Case 3. 


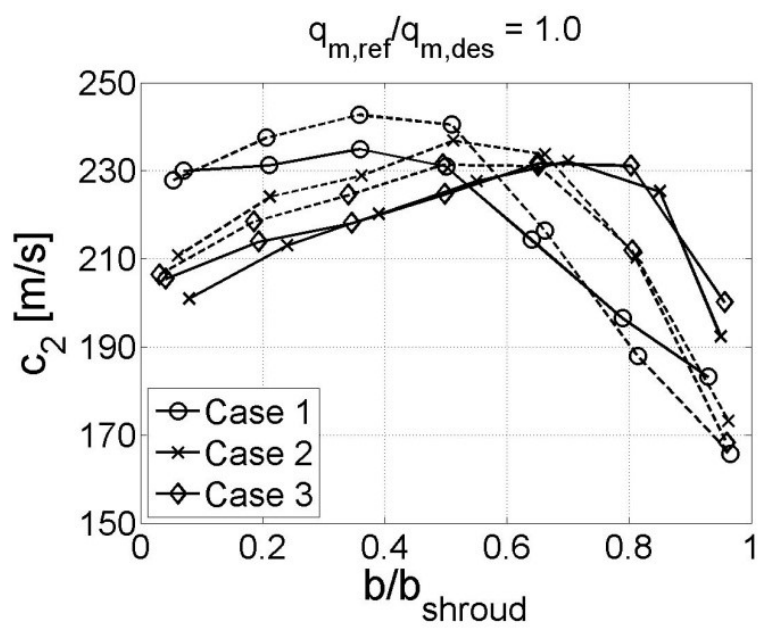

(a)

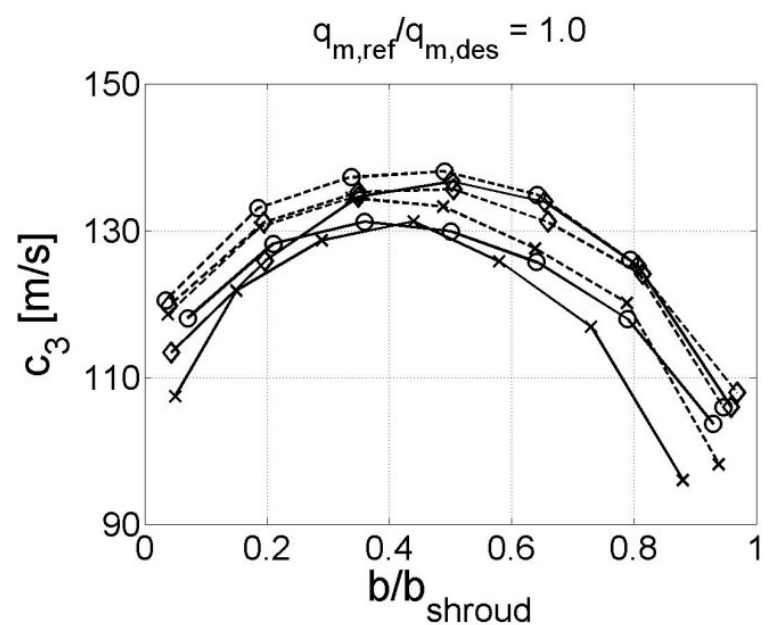

(b)

Fig. 9 Absolute flow velocities at the lowest (solid line) and highest (dashed line) tip clearances, (a) diffuser inlet and (b) diffuser outlet

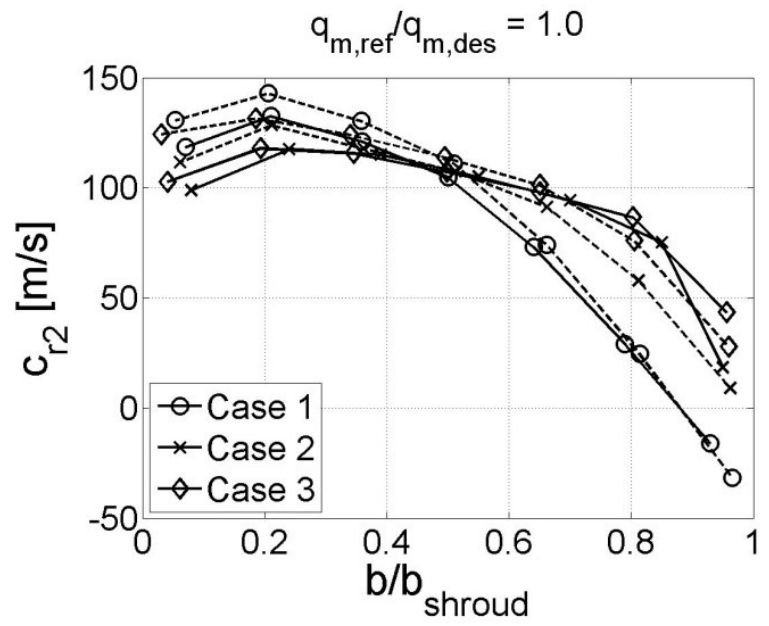

(a)

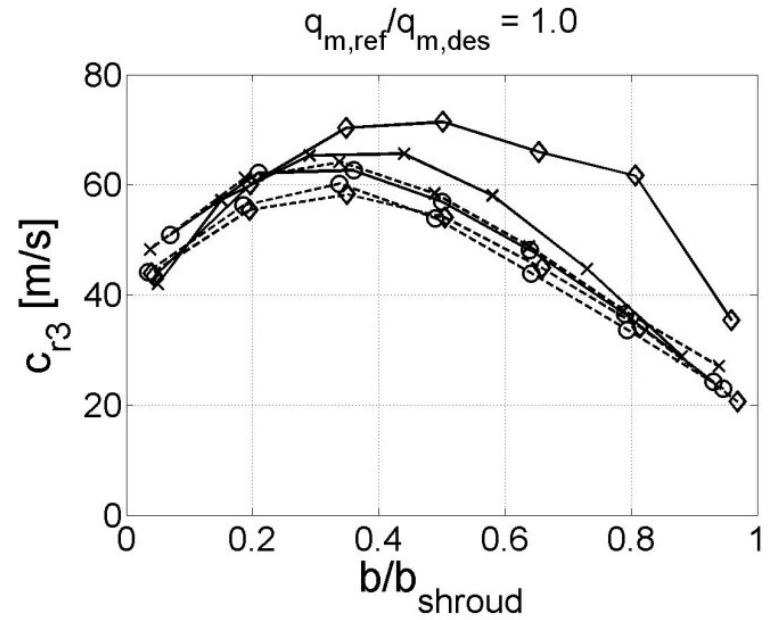

(b)

Fig. 10 Radial velocities at the lowest (solid line) and highest (dashed line) tip clearances, (a) diffuser inlet and (b) diffuser outlet

The absolute flow velocities with the highest and lowest clearances are presented in Figure 9. At the diffuser inlet, it is evident that the increasing tip clearance alters the flow field. The secondary flow 
region near the shroud is clearly larger with the higher tip clearance. The larger secondary flow region forces the flow to accelerate near the hub in order to pass the same flow rate through. This is seen as higher velocities near the hub with the higher clearance. The pinch accelerates the flow, and this is clearly seen as higher velocities near the shroud. On the other hand, the velocities near the hub are lower with the pinch. All in all, the higher flow velocity near the shroud and lower velocity near the hub mean that there is less shear stress, and thus the losses are lower with the pinch. The effect of the increasing tip clearance is more profound when there is a pinch. At the diffuser outlet, the velocity is higher with the increased clearance throughout the diffuser width. With Case 3, the differences caused by the increasing tip clearance are marginal near the shroud. The effect of the increased tip clearance at the diffuser outlet is highest with Case 1.

The radial velocities are obtained with the flow angles and the flow velocities. The radial velocity with the minimum and maximum clearances at the diffuser inlet and outlet is shown in Figure 10. At the diffuser inlet, the radial velocity is higher near the hub when the clearance is larger. As the secondary flow region was larger, it pushed the core flow towards the hub, and this is seen as an increase in the radial velocity. The radial velocity and flow angles at the diffuser inlet are important if a vaned diffuser is designed, as the incidence at the diffuser inlet is one of the defining parameters.

For Case 1, the tip clearance hardly affects the radial velocity near the shroud. With the pinch (Cases 2 and 3) the clearance has some effect on the radial velocity near the shroud. At the diffuser outlet, the effect of the clearance is seen for Case 3. The flow is clearly more radial, and therefore, the mass flow distribution is more uniform for Case 3 with the smallest clearance. 


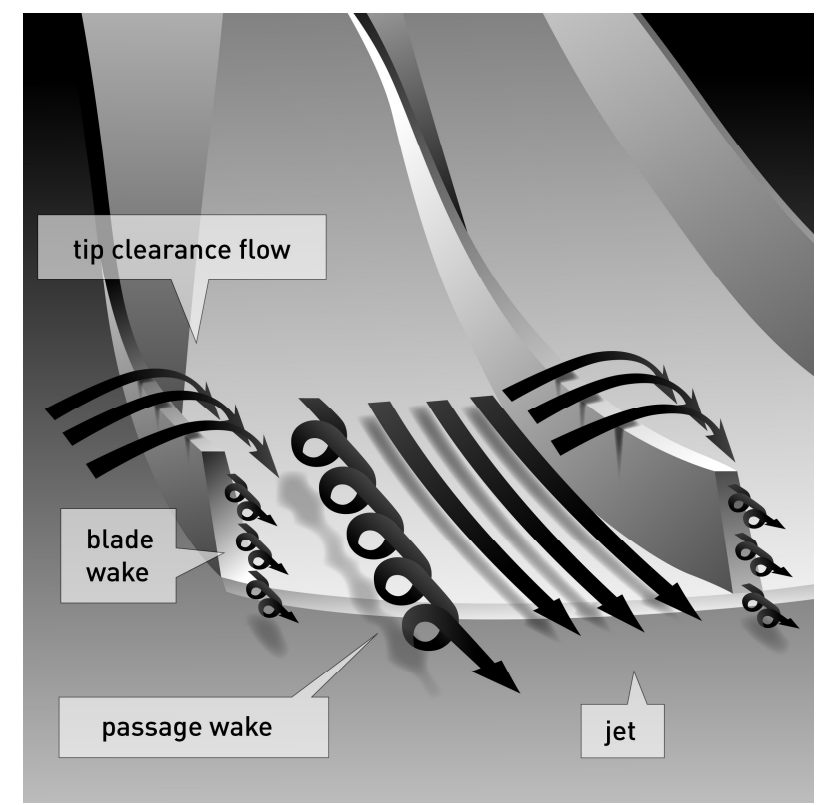

Fig. 11 An illustration of the flow field at the impeller outlet.

\subsubsection{Summary of diffuser flow fields}

An illustration of the flow field at the impeller outlet, showing the main flow (jet), secondary flows (passage and blade wakes), and the tip clearance flow, is presented in Fig. 11. The pinch reduced the secondary flow region present near the shroud at the impeller outlet. As the secondary flow region was accelerated due to the pinch, there is less shear stress, and thus lower losses occur with the pinch.

Increasing the tip clearance led to a larger secondary flow region, and the core flow was pushed towards the hub, resulting in higher radial velocity there. From the results it is evident that the pinch helps with the adverse effects caused by the clearance flow. 
The overall effects of the tip clearance and pinch seem to boil down to the following. The tip clearance causes a momentum deficit near the shroud and induces higher velocities near the hub due to the continuity. This causes a higher strain rate in the flow, thus causing more kinetic energy to be dissipated into turbulence and higher viscous losses. The shroud pinch accelerates the flow near the shroud and possibly suppresses the tip clearance vortex. This reduces the strain rate, resulting in lower losses.

It seems that the lowest tip clearance in Case 3 showed improvements superior to the other two cases. With a larger tip clearance the effects were not that much different. It could be speculated that the pinches used were not large enough to suppress the tip vortex with the other cases.

\section{CONCLUSIONS AND DISCUSSION}

The overall stage performance and the flow fields at the diffuser inlet were studied for three different diffusers and four tip clearances for each diffuser. The diffuser widths $b /\left(b_{2}+t_{2}\right)$ were 1.0, 0.903, and 0.854 . The four clearances $t_{2} / b_{2}$ used were $0.027,0.053,0.082$, and 0.106 . The tip clearance was altered by shimming the shroud side casing, and the diffuser width was changed by pinching the shroud side wall.

The overall stage performance was measured according to relevant standards. The axial total pressure and temperature distributions before and after the diffuser were measured with Kiel and cobra probes, and in addition, the static pressures were measured adjacent to the probe measurements.

Regarding the hypothesis: 
1. Pinch did improve the total-to-total stage efficiency, but it did not change the qualitative behaviour, meaning that the efficiency decreased similarly with the increasing tip clearance with or without the pinch. It is thus deduced that in centrifugal compressors, the tip clearance wake is not the main cause of losses in diffuser, but it is mixed out in the impeller.

2. Flow turned more radial and travelled a shorter path through the diffuser, and no hub side separation due to the increased opening angle was detected. This indicates that the tested pinches were small enough not to cause the flow to separate.

In general, the pinch suppressed the slow momentum region present near the shroud at the impeller exit, and thus enhanced the mixing of the axial variations which, according to the literature survey, tended to persist. As the wake in the shroud is suppressed, the strain in the diffuser is lower, and the flow accelerates less near the hub. This results in lower losses, and is seen as higher stage efficiency.

Without a doubt, a moderate pinch improves the stage efficiency. In this study, the highest efficiency gain with the pinch was approximately two percentage points at the design operating point, and approximately three percentage points at slightly higher mass flows. However, according to the literature, an excessive pinch deteriorates the efficiency. This is most likely due to the separation in the diffuser caused by the acceleration of the flow, and the increase in the opening angle due to the narrower diffuser. Further research is still needed to discover whether an optimum pinch can be found, and which are the factors it depends on.

Furthermore, the decrease in the flow area leads to the acceleration of the flow at the diffuser outlet. The flow acceleration decreases the boundary layers, resulting in lower boundary layer losses. 
However, the boundary layers cannot be studied with the setup used in the present study, and the change in the losses due to the smaller boundary layer is minor.

Further research is needed to separate in more detail the effect of tip clearance vortex and jet as well as their effect on the flow fields.

\section{FUNDING}

The authors would like to gratefully acknowledge the financial support of the Academy of Finland, the Finnish Funding Agency for Technology and Innovation - TEKES, and High Speed Tech Oy Ltd (currently part of Sulzer Pump Solutions Finland Oy).

(C) Authors

\section{REFERENCES}

[1] Kim Y, Engeda A, Aungier R, and Amineni N. A centrifugal compressor stage with wide flow range vaned diffusers and different inlet configurations. Proc. Inst. Mech. Eng., A J. Power Energy 2002; 216: 307-320.

[2] Issac JM, Sitaram N, and Govardhan M. Performance and wall static pressure measurements on centrifugal compressor diffusers. Proc. Inst. Mech. Eng., A J. Power Energy 2003; 217: $547-558$.

[3] Senoo Y and Kinoshita Y. Influence of inlet flow conditions and geometries of centrifugal vaneless diffusers on critical flow angle for reverse flow. J. Fluids Eng. 1977; 99: 98-103. 
[4] Van den Braembussche R, Fringe P, and Roustan M. Rotating Non-Uniform Flow in Radial Compressors. In AGARD 55 ${ }^{\text {th }}$ Specialist meeting of PEP, 282, Brussels, Belgium, May 79, 1980, paper no 12 .

[5] Ludtke K. Aerodynamic tests on centrifugal process compressors - the influence of the vaneless diffusor shape. J. Eng. Power 1983; 105: 902-909.

[6] Ferrara G, Ferrari L, Mengoni CP, Lucia MD, and Baldassarre L. Experimental investigation and characterization of the rotating stall in a high pressure centrifugal compressor: Part I: Influence of diffuser geometry on stall inception. In proceedings of ASME Turbo Expo, Amsterdam, The Netherlands, June 3-6, 2002, paper GT2002-30389.

[7] Ferrara G, Ferrari L, Mengoni CP, Lucia MD, and Baldassarre L. Experimental investigation and characterization of the rotating stall in a high pressure centrifugal compressor: Part II: Influence of diffuser geometry on stage performance. In proceedings of ASME Turbo Expo, Amsterdam, The Netherlands, June 3-6, 2002, paper GT2002-30390.

[8] Cellai A, Ferrara G, Ferrari L, Mengoni CP, and Baldassarre L. Experimental Investigation and Characterization of the Rotating Stall in a High Pressure Centrifugal Compressor Part III: Influence of Diffuser Geometry on Stall Inception and Performance (2nd Impeller Tested. In proceedings of ASME Turbo Expo, Atlanta, USA, June 16-19, 2003, paper GT2003-38390. 
[9] Di Liberti JL, Wilmsen B, and Engeda A. The effect of the vaneless diffuser width on the performance of a centrifugal compressor. In proceedings of Fluids Engineering Division Conference, ASME, FED, 237, 797-803, 1996.

[10] Jaatinen A, Grönman A, Turunen-Saaresti T, and Röyttä P. Effect of Vaneless Diffuser Width on the Overall Performance of a Centrifugal Compressor. Proc. Inst. Mech. Eng., A J. Power Energy 2011; 225: 665-673.

[11] Turunen-Saaresti T, Grönman A, and Jaatinen A. Experimental Study of Pinch in Vaneless Diffuser of Centrifugal Compressor. In proceedings of ASME Turbo Expo, Orlando, USA, June 8-12, 2009, paper GT2009-60162.

[12] Pinarbasi A and Johnson MW. Detailed Flow Measurements in a Centrifugal Compressor Vaneless Diffuser. J. Turbomach. 1994; 116: 453-461.

[13] Pinarbasi A and Johnson MW. Off-Design Flow Measurements in a Centrifugal Compressor Vaneless Diffuser. J. Turbomach. 1995; 117: 602-608.

[14] Pinarbasi A and Johnson MW. Detailed Stress Tensor Measurements in a Centrifugal Compressor Vaneless Diffuser. J. Turbomach. 1996; 118: 394-399.

[15] Pinarbasi A. Turbulence measurements in the inlet plane of a centrifugal compressor vaneless diffuser. Int. J. Heat Fluid Flow 2009; 30: 266-275.

[16] Pampreen R. Small turbomachinery compressor and fan aerodynamics. J. Eng. Power 1973; 95: 251-156. 
[17] Eisenlohr G and Chladek H. Thermal tip clearance control for centrifugal compressor of an APU engine. J. Turbomach 1994; 116: 629-634.

[18] Palmer DL and Waterman WF. Design and development of an advanced two-stage centrifugal compressor. J. Turbomach 1995; 117: 205-212.

[19] Hong SS, and Abhari R. Effect of tip clearance on impeller discharge flow and vaneless diffuser performance of a centrifugal compressor Proc. Inst. Mech. Eng., $A J$. Power Energy Epub ahead of print 8 August, 2012 DOI: 10.1177/0957650912455386.

[20] Turunen-Saaresti T and Jaatinen A. Influence of the different design parameter to the centrifugal compressor tip clearance loss. J. Turbomach 2013; 135: 011017.

[21] Mashimo T, Watanabe I, and Ariga I. Effects of fluid leakage on performance of a centrifugal compressor. J. Eng. Power, 1979; 101: 337-342.

[22] Senoo Y and Ishida M. Deterioration of compressor performance due to tip clearance of centrifugal impellers. J. Turbomach 1987; 109: 55-61.

[23] Schleer M and Abhari R. Clearance effects on the evolution of the flow in the vaneless diffuser of a centrifugal compressor at part load condition. J. Turbomach 2008; 130: 031009.

[24] Wang HL, Xi G, Li JY, and Yuan MJ. Effect of the tip clearance variation on the performance of a centrifugal compressor with considering impeller deformation. Proc. Inst. Mech. Eng., A J. Power Energy 2011; 225: 1143-1155. 
[25] You M, Wang M, Moin P, and Mittal R. Large-eddy simulation analysis of mechanisms for viscous losses in a turbomachinery tip-clearance flow. J. Fluid Mech. 2007; 586: $177-204$

[26] Denton J. Loss mechanisms in turbomachines. J. Turbomach 1993; 115: 621-656.

[27] Jaatinen A, Turunen-Saaresti T, Grönman A, Röyttä P, and Backman J. Experimental study of the effect of the tip clearance to the diffuser flow field and stage performance of a centrifugal compressor. In proceedings of ASME Turbo Expo, Copenhagen, Denmark, June 11-15, 2012, paper GT2012-68445.

[28] DIN 1952:1971 Durchflußmessung mit genormten Düsen, Blenden und Venturidüsen. Deutsches Institut für Normung e.V.

[29] ASME PTC 10:1997. ASME Power Test codes, compressors and exhausters. The American Society of Mechanical Engineering.

[30] ISO 5389:2005 Turbocompressors - Performance test code. International Stardardization Organization.

[31] VDI 2045 Part 1:1993. Abnahme- und Leistungsversuche an Verdichtern, Versuchsdurchführung und Garantievergleich (Acceptance and Performance Test on Turbo Compressors and Displacement Compressors, Test Procedure and Comparison with Guaranteed Values). Verein Deutscher Ingenieure. 
[32] VDI 2045 Part 2:1993. Abnahme- und Leistungsversuche an Verdichtern, Grundlagen und Beispiele (Acceptance and Performance Test on Turbo Compressors and Displacement Compressors, Theory and examples. Verein Deutscher Ingenieure.

\section{APPENDIX}

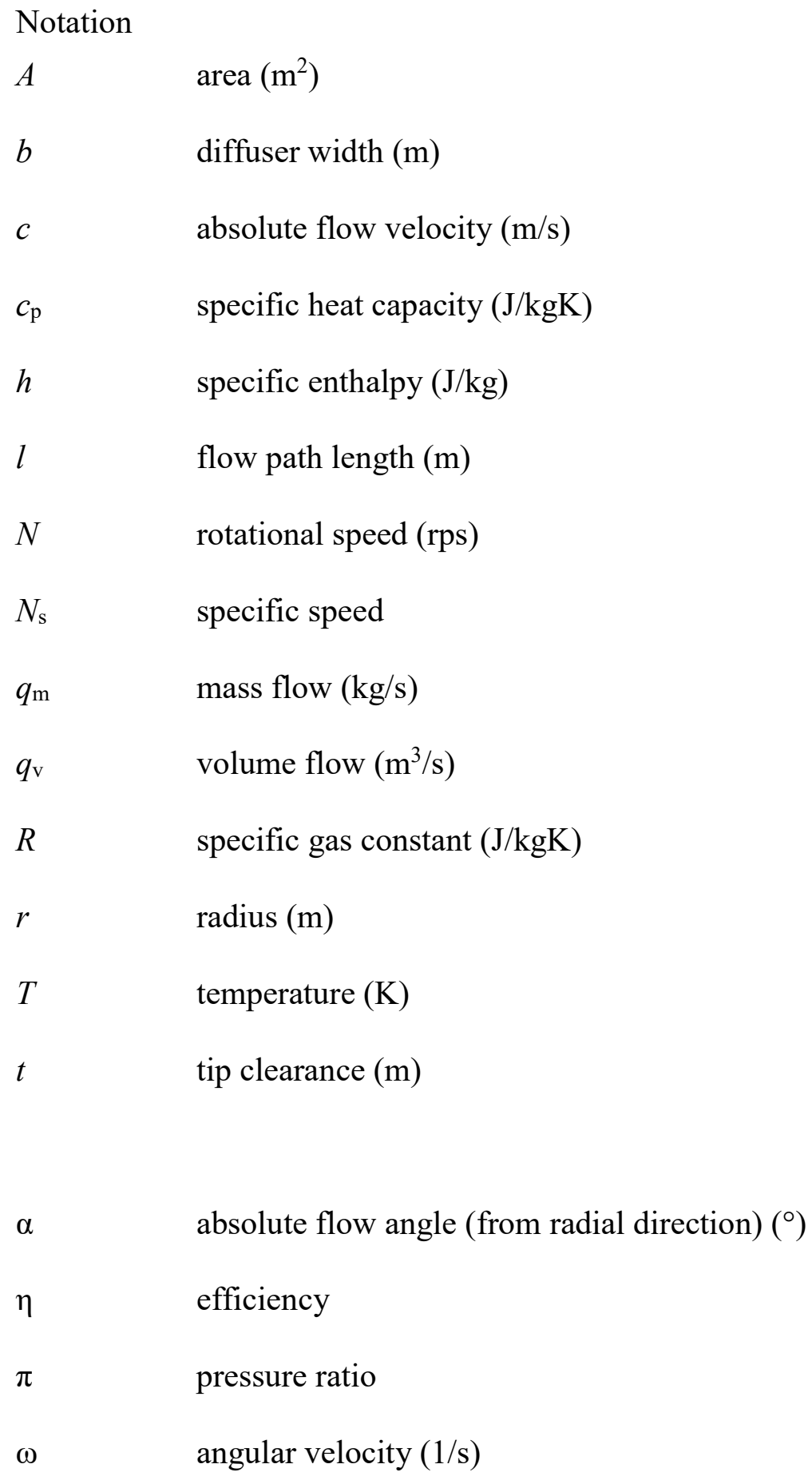




$\begin{array}{ll}\text { Subscripts } & \\ 1 & \text { compressor inlet } \\ 2 & \text { impeller outlet } \\ 2 & \text { beginning of the pinch } \\ 3 & \text { diffuser outlet } \\ 5 & \text { compressor outlet } \\ \text { des } & \text { design value } \\ \text { ref } & \text { reference value } \\ \text { r } & \text { radial component } \\ \text { s } & \text { isentropic } \\ \text { t } & \text { total state }\end{array}$

